\title{
Notas sobre o Grupo de Estudos e Pesquisas em Política Educacional - GREPPE
}

\author{
Notes about Group of Studies and Research in Educational \\ Policy - GREPPE
}

\section{Theresa Adrião ${ }^{1}$}

"Um galo sozinho não tece uma manhã: ele precisará sempre de outros galos. De um que apanhe esse grito que ele e o lance a outro; de um outro galo que apanhe o grito de um galo antes e o lance a outro; e de outros galos

que com muitos outros galos se cruzem os fios de sol de seus gritos de galo, para que a manhã, desde uma teia tênue, se vá tecendo, entre todos os galos..." (João Cabral de Melo Neto, Tecendo a manhã )

\section{Resumo:}

O artigo apresenta a trajetória de constituição do Grupo de Estudos e Pesquisas em Política Educacional - GREPPE, iniciada em princípios da década de 2000. Desde a necessidade objetiva de se construir um espaço que abrigasse o esforço coletivo de diversos pesquisadores, mais experientes e iniciantes, até a disposição em desenvolver ações e lutas inclusive políticas na defesa da educação pública de qualidade para todos, o grupo tem assumido um conjunto amplo e diverso de estudos e intervenções no campo da pesquisa em políticas educacionais.

Palavras-chave: Políticas educacionais; Pesquisa; GREPPE.

\begin{abstract}
:
The article presents the history of Group of Studies and Research in Educational Policy - GREPPE, started in early 2000s. Since the objective necessity to build a space that housed the collective efforts of many researchers, most experienced and beginners, until the inclination to develop actions and fights, political inclusive, in defense of quality public education for all, the group has taken a broad and diverse set of studies and interventions in the research field in educational policies.
\end{abstract}

Keywords: Education policies; Research; GREPPE.

1 Doutora em Educação (USP). Professora da Universidade Estadual de Campinas (UNICAMP). theadriao@gmail.com. 
O GREPPE (Grupo e Estudos e Pesquisas em Política Educacional) surgiu de uma necessidade objetiva, de uma perspectiva política e de aprendizados. Razões suficientes que se apresentaram não necessariamente nesta mesma ordem e nem de forma excludente...

\section{Necessidade objetiva}

No final dos anos de 1990, com o término do doutorado, o qual ainda se constituía como exercício individual, atuava como professora na área de política educacional e dividia preocupações com Maria Aparecida Segatto Muranaka, sobre o Ensino Superior no Departamento de Educação da UNESP, de Rio Claro- SP.

Como egressa da rede pública em educação básica, trazia como práxis as reivindicações das esferas coletivas de organização do trabalho e a participação efetiva do Grupo de Estudos e Pesquisas em Administração em Educação (GEPAE), espaço de formação e discussão coletiva coordenado pelo Prof. Vitor Paro e por seus orientandos. Ressentiame, diante desse percurso constituído, observar a inexistência de perspectivas coletivas de pesquisa no âmbito universitário, pois o Departamento era pequeno e todos tinham trajetórias definidas.

A alternativa para agregar o interesse em estudar políticas em educação básica com a necessidade de trabalhar coletivamente foi vincular-me a uma pesquisa nacional, de caráter interinstitucional com o objetivo de analisar as consequências do Fundo de Manutenção e Desenvolvimento do Ensino Fundamental e Valorização do Magistério (FUNDEF), na oferta de educação básica em diferentes Estados e municípios brasileiros. A pesquisa nacional foi coordenada pelos Profs. Beatriz Luce, Lisete Arelaro e Romualdo Portela Oliveira com o apoio da Fundação Ford e de várias agências estaduais de fomento. Contei com o apoio de duas bolsistas de Iniciação Científica subsidiadas pela Fapesp e de uma estagiária recém-formada. Egle Pessoa Bezerra e Adriana Dragone Silveira, duas das três integrantes dessa pesquisa, ainda hoje compõem o grupo e são, respectivamente, mestre e doutora em educação. O GREPPE (Grupo de Estudos e Pesquisas em Políticas Educacionais) se iniciava. A participação nessa pesquisa (2001-2003) teve como mérito integrar um conjunto de pesquisadores de distintas instituições brasileiras organizados em redes para o desenvolvimento de pesquisas de natureza interinstitucional. Após conclusão do estudo sobre o Fundef, uma dessas redes, se articulou em torno da pesquisa interinstitucional Programa Dinheiro Direto na Escola (PDDE): uma proposta de redefinição do papel do Estado? coordenada pela profa. Vera Maria Vidal Peroni (UFRGS) e por mim, na qual se analisou as consequências do PDDE para a gestão e o financiamento de escolas públicas em cinco Estados e dez municípios do Brasil. Da pesquisa financiada pelo CNPq e publicada pelo INEP em 2007, participaram distintos centros coordenados localmente por Rosana Cruz- UFPI, Liliene Luz- UEPI, Terezinha Silva UFPA, Teise Garcia- USP-RP e Regina Cestari (UCDB).

Em São Paulo, a investigação se deu no âmbito do Greppe e contou com alunos de graduação e de mestrado que, ainda hoje, estão vinculados à pesquisa educacional e ao grupo, alguns 
deles já como professores de universidades.

Paralelamente ao Greppe se desenvolveu uma linha de investigação sobre Ensino Médio noturno ofertado nas escolas públicas de São Paulo², no segundo semestre de 2003. Como em outra oportunidade esta pesquisa também se vinculou a uma investigação nacional sob a responsabilidade dos Profs. Sandra Zakia de Souza, Romualdo Portela de Oliveira e Valéria Virginia Lopes, financiada pela UNESCO e pelo MEC. Essas experiências interinstitucionais de pesquisa reforçaram a crença na superioridade do trabalho coletivo em relação ao esforço individual.

Por ter um percurso de pesquisas interinstitucional constituído e, principalmente por fazer parte de um grupo sob minha coordenação e a da Profa. Teise Garcia, o GREPEE foi incorporado ao Diretório de Grupos de Pesquisa do CNPq em 2005. Já em 2006 o ingresso da Profa. Raquel Borghi à UNESP ao grupo reafirmou a perspectiva delineada desde 2001, segundo a qual as pesquisas devem ser coletivas e interinstitucionais, precisam envolver estudantes em diferentes estágios de formação e necessitam dialogar com as atividades de extensão. Parte desse processo está indicada no site http://www.rc.unesp. $\mathrm{br} / \mathrm{ib} / \mathrm{educacao/greppe.}$

\section{Perspectiva política}

Uma das perspectivas do GREPPE é construir uma dinâmica de produção científica que se constitua como espaço de formação de novos pesquisadores, articulados na divulgação de experiências na área do conhecimento com o objetivo de estimular o debate qualificado no campo da política educacional, com o compromisso de defesa do direito à educação pública de qualidade para todos. Esta é uma opção política.

Assim, assumimos o compromisso de organizar a cada dois anos Seminários de Pesquisa que permitam o debate ampliado sobre tema abordado nas investigações em andamento do grupo. Para tanto, temos contado com a participação de pesquisadores de distintos centros de investigação, brasileiros e estrangeiros em mesas redondas ou conferências relacionadas aos temas focalizados em nossas investigações. Até 2011, os Seminários tiveram lugar na UNESP de Rio Claro, versavam sobre os seguintes temas: Autonomia e Regulações da Escola (2007); Interfaces entre o Público e o Privado para a Oferta Educacional (2009); e, Organização do trabalho na escola e reformas educativas (2011). Mas sem a participação ativa e dos alunos, especialmente da graduação, na coordenação da infraestrutura e na operacionalização dos mesmos, esses Fóruns não ocorreriam.

Além dos fóruns apontados acima, o Greppe protagonizou um evento considerado um dos mais importantes. Trata-se de um seminário interinstitucional e itinerante que envolveu quatro campi da UNESP, a FE-UNICAMP, a FEUSP e a USP-RP com transmissão simultânea,

2 ADRIÃo, T. Ensino médio noturno em São Paulo: democratização e diversidade / coordenação estadual. Brasília: Ministério da Educação, Secretaria de Educação Básica, 2006, p.94. Disponível em http://portal.mec.gov.br/index.php?option=com_content\&view=article\&id=16383\&ltemid=859. 0 relatório nacional foi recentemente distribuído pelo MEC/SEB a todas as escolas públicas de Ensino Médio no Brasil. 
via teleconferência, de mesas redondas realizadas em três cidades diferentes para os polos envolvidos. Nesse evento contamos com a ousadia de colegas professores como: Raquel Borghi, Eugênio Ramos, Regiane Bertagna, Nora Krawczyk, Pedro Ganzeli, Romualdo P Oliveira, Teise Garcia, Graziela Zambão, João Gentilini, José Luiz Guimarães; de técnicos; e, de alunos das referidas instituições. Em 2007 ocorreu O Plano de Desenvolvimento da Educação (PDE) em debate nas universidades paulistas, no qual compareceram pesquisadores como: Celso de R. Beisegel, Lisete Arelaro, Romualdo Portela Oliveira, Luiz Carlos Freitas, Nigel Brooks, Marcio da Costa, Silke Weber, Luiz Araújo, Otaviano Helene, Sergio Haddad, Reinaldo Fernandes e Marcia Ângela Aguiar, além da presença dos representantes do MEC para o aprofundamento do debate dos temas do PDE.

Diante dos limites institucionais decorrentes de sua localização do Departamento de Educação no Instituto de Biociências, conseguimos, com esforços coletivos, articular e ousar a constituição desses eventos ressaltando a importância da opção política pela organização e pelo investimento em grupos de pesquisas conectados em torno de interesses acadêmicos e de compromissos políticos.

Também expressa nossa opção por uma política de formação de pesquisadores coletiva a realização de seminários de pesquisas relacionados aos projetos de investigação em andamento, nos quais pesquisadores doutores e estudantes de todos os níveis submetem ao debate e à rigorosa, mas solidária, crítica suas produções.

\section{Aprendizados...}

"Rodiziando" papéis e funções (ora coordenando, ora sendo coordenados), acreditamos vivenciar um nicho democrático da vida acadêmica, que sem deixar de primar pela produção de qualidade e inovadora, confronta-se com a lógica individualista e produtivista hoje imperante na universidade." (Adrião, 2012, p. 32, Mimeo)

Entre 2007-2009 desenvolvemos a pesquisa Estratégias municipais para a oferta da educação básica: uma análise de parcerias público-privado no estado de São Paulo financiada pela FAPESP (2006-2009) cuja responsabilidade dividi com as professoras Teise Garcia, Lisete Arelaro e Raquel Borghi; com a participação de cinco mestrandos e mais de 10 graduandos. Os resultados repercutiram na mídia impressa e podem ser também apreendidos pelos inúmeros artigos e trabalhos apresentados, tanto pelos pesquisadores responsáveis, quanto pelos alunos de graduação e mestrado articulados ao projeto. No entanto, talvez a maior contribuição do projeto tenha sido do Banco de Dados Parcerias Público-Privadas e Municípios Paulistas, constituído por informações sobre a relação entre os 645 municípios e a esfera privada para a gestão e o financiamento da educação básica. O Banco encontra-se disponível em http://www.fae.unicamp.br/greppe/bd/pesquisas/ pesqdados.php. A atualização dos dados do banco continua na pauta das tarefas, por isso contamos com o auxílio de bolsistas de IC de diferentes seções muitos dos quais deram continuidade a sua inserção na pesquisa em política educacional ao ingressarem em 
mestrados acadêmicos.

Como consequência desta pesquisa, o GREPPE desenvolveu, concomitantemente, três projetos de pesquisa ambientados em São Paulo, financiados pelo CNPq e pela Fapesp, entre anos de 2010 e 2012. O primeiro foi intitulado de: As parcerias público-privado para a compra de "sistemas de ensino": análise das consequências para a organização do trabalho na escola, coordenado por Teise Garcia e Bianca Correa; o segundo coordenado por Raquel Borghi e Regiane Bertagna denominou-se Oferta Educacional na Educação Infantil: novos arranjos institucionais entre o público e o privado; e, o terceiro coordenado por mim foi denominado como: Sistemas Apostilados de Ensino e Municípios Paulistas: O Avanço do Setor Privado Sobre a Política Educacional Local. Todos contaram com a participação de alunos de graduação e de pós-graduação das diferentes universidades, além das contribuições da Profa Lisete Arelaro, da Feusp.

Objetivava-se com essa iniciativa um tanto frenética - dadas as exigências demandadas para cada um dos pesquisadores que simultaneamente coordenariam projetos e integrariam projetos como pesquisadores - consolidar as seções do Grupo de pesquisa que passaram a existir a partir de 2009, com o desenvolvimento dos três projetos de pesquisa: GREPPEUNESP-RC, coordenado pela Raquel Borghi e pela Regiane Bertagna, GREPPE_USP-RP, coordenado por Teise Garcia e Bianca Correa e criado em 2008 e o GREPPE- UNICAMP, coordenado por mim.

Foi neste contexto que as professoras Regiane Bertagna e Bianca Correa se incoporaram ao Grupo, agregando suas experiências ao funcionamento do GREPPE.

As atividades de pesquisa em rede se mantem em plano nacional, em 2008, eu e a Profa. Vera Peroni iniciamos a elaboração de um novo projeto interinstitucional de âmbito nacional, no qual o grupo, composto basicamente pela mesma equipe de pesquisadores envolvidos no PDDE: Vera Peroni, Teise Garcia, Regina Cestari, Liliene Luz, Terezinha Fátima Santos e Dalva Gutierres. No entanto, contamos agora com a colaboração de novos pesquisadores: Maria Vieira, Lisboa Leitão de Souza, Silvana Souza, Maria Dilnéia Fernandes, Margarita Rodriguez, Lisete Arelaro e Marilda Costa. Além de estudantes de pós-graduação e graduação articulados a cada grupo local. De certa forma, a questão de pesquisa que nos persegue é a mesma dos projetos anteriores e refere-se às novas interfaces entre a esfera pública/estatal e a privada para a oferta a gestão da educação básica. O Projeto Análise das consequências de parcerias firmadas entre municípios brasileiros e a Fundação Ayrton Senna para a oferta educacional financiado pelo CNPq foi concluído em 2011.

No biênio 2012-2014, o Greppe desenvolverá a pesquisa PDE-Escola e suas implicações para a organização e a gestão democrática da educação básica, coordenada nacionalmente por Regina Cestari e Vera Peroni e no âmbito do estado de São Paulo por Teise Garcia.

Paralelamente, sob a minha coordenação, o Greppe UNICAMP mantém a atualização do Banco de Dados. Ainda que de "modo combinado e desigual", temos tentado instituir uma lógica de trabalho coletivo, interinstitucional e não personalista, no qual as diferenças e divergências 
se resolvem de forma apaixonada, solidária e que se assenta no respeito e na confiança de elementos indispensáveis à produção acadêmica.

\section{Sítios na web referenciados}

http://www.rc.unesp.br/ib/educacao/greppe/

http://www.fe.unicamp.br/lage/greppe/index.html

http://sites.ffclrp.usp.br/grepperp/quem_somos.html

http://portal.mec.gov.br/index.php?option=com content\&view=article\&id=16383\&ltemid=859

Recebido em setembro de 2012 Aprovado em novembro de 2012 